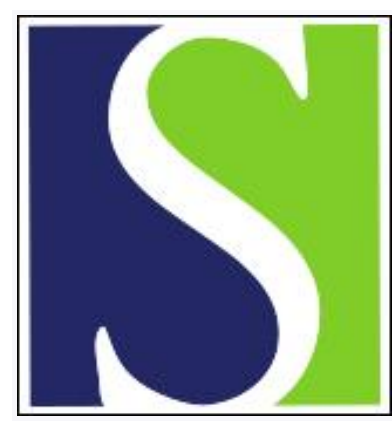

Scand J Work Environ Health 2002;28(3):163-167

https://doi.org/10.5271/sjweh.660

Issue date: Jun 2002

Ten-year update on mortality among mild-steel welders by Steenland K

Affiliation: National Institute for Occupational Safety and Health (NIOSH), 4676 Columbia Parkway, Cincinnnati, OH 45226, United States.nsteenland@cdc.gov

Refers to the following text of the Journal: 1997;23(2):104-113

The following article refers to this text: 2007;33(5):379-386

Key terms: lung cancer; mild-steel welder; mortality; welding

This article in PubMed: www.ncbi.nlm.nih.gov/pubmed/12109555 


\title{
Ten-year update on mortality among mild-steel welders
}

\author{
by Kyle Steenland, $P h D^{1}$
}

\begin{abstract}
Steenland K. Ten-year update on mortality among mild-steel welders. Scand J Work Environ Health 2002;28(3):163-167.
\end{abstract}

Objectives This study is an update on the lung cancer risk of mild-steel welders with no asbestos exposure using a cohort of nonwelders for comparison.

Methods The subjects came from three United States (US) plants that manufactured heavy equipment. The follow-up was extended from 1988 to 1998. The welders were not exposed to asbestos (typical of shipyard welders) or to chromium or nickel (present in stainless steel).

Results There were 108 lung cancer deaths among the welders and 128 such deaths among the nonwelders (double the previous number of lung cancer deaths). The standardized mortality ratio (SMR) for lung cancer was 1.46 [95\% confidence interval (95\% CI 1.20-1.76] for the welders and 1.18 (95\% CI 0.98-1.40) for the nonwelders, both in comparison with the US general population. Direct comparison between the welders and nonwelders yielded a rate ratio of 1.22 (95\% CI 0.93-1.59). Analyses using a 15-year lag time did not differ greatly from those of an unlagged analysis. There were no marked trends for lung cancer risk by duration of exposure or latency. Evidence from cross-sectional data from a sample of the cohort indicated that the welders smoked somewhat more than the US population and more than the nonwelders. An approximate adjustment of the rate ratios for possible confounding by smoking suggested that smoking may have accounted for about half of the excess lung cancer observed among the welders versus that of either reference population.

Conclusions These data provide suggestive but not conclusive evidence of a modest lung cancer risk from mild-steel welding.

Key terms lung cancer, welding.

In 1991 my colleagues and I published our findings for a cohort of 4459 mild-steel welders and a companion cohort of 4286 other workers who were never welders but who worked in the same three heavy equipment plants (1). The welders were of interest because they had not been exposed to asbestos (typical of shipyard welding) or nickel and chromium (present in stainless steel welding). These agents were potentially responsible for findings of excess lung cancer in other welder cohorts. According to approximately 300 samples taken in 19741987 , the welders in our cohort were exposed to a dust concentration of approximately $6 \mathrm{mg} / \mathrm{m}^{3}$ and an iron oxide concentration of $3 \mathrm{mg} / \mathrm{m}^{3}$. Sampling conducted in the late 1980s for 28 nonwelders indicated that they were exposed to these two substances at levels that were an order of magnitude lower than the welders' exposures.

Both the welder and nonwelder cohorts were restricted to those who had worked at least 2 years (2 years in welding for the welders). The average duration of welding was 8.5 years for the welders. In the original study, follow-up had been extended through 1988, and $12 \%$ of the combined cohorts had died $(\mathrm{N}=1067)$. The average time since first welding exposure was 20 years for the welders at the time of the first follow-up.

In 1991 the welders had a standardized mortality ratio (SMR) of 1.07 [95\% confidence interval (95\% CI 0.76-1.46), 39 observed] for lung cancer, while the corresponding ratio for the nonwelders was $1.17(95 \% \mathrm{CI}$

1 National Institute for Occupational Safety and Health (NIOSH), Cincinnati, Ohio, United States.

Reprint requests to: Dr Kyle Steenland, National Institute for Occupational Safety and Health (NIOSH), 4676 Columbia Parkway, Cincinnati, OH 45226, United States. [E-mail: nsteenland@cdc.gov] 
0.92-1.47, 74 cases observed). A direct comparison of the welders and nonwelders yielded a rate ratio of 0.90 (95\% CI 0.60-1.36). For the welders, there were no marked trends for either duration of welding or time since welding (latency). Limited smoking data indicated that both cohorts smoked slightly more than the United States (US) population.

In the last 10 years there have been numerous publications regarding lung cancer and welding. Moulin (2) summarized many of these in a meta-analysis of 36 studies, in which he concluded that welders have an approximately 30-40\% excess risk of lung cancer, which did not appear to be concentrated among either shipyard welders or stainless steel welders. Moulin estimated that smoking differences were likely to account for an excess risk of approximately $20 \%$ in the cohort studies, which were perhaps less subject to bias and more certain of exposure than the case-referent studies. Thus there appeared to be a modest excess of lung cancer above the effects of smoking, an excess which could not be readily explained as being due either to asbestos or to the nickel and chromium in stainless steel welding.

I have now updated the data on our own mild-steel welding cohort with 10 years of further follow-up, resulting in 1969 deaths (23\% of the cohort), of which there were 108 lung cancer deaths among the welders and 128 lung cancer deaths among the nonwelders.

\section{Subjects and methods}

A full description of the welder and nonwelder cohorts is given in our earlier publication (1). Briefly, the welders had $\geq 2$ years of welding experience welding heavy equipment at three plants in the midwestern United States. The nonwelders worked in the same plants and were assemblers, inspectors, packers, janitors, or electric forklift drivers. The nonwelders were required to have worked $\geq 2$ years. All three plants began operation in the 1950s. All cohort members were male, and $90 \%$ were white.

I conducted the new follow-up from 1989-1998 using death tapes of the Social Security Administration and data from the National Death Index (NDI). Deaths were coded into the ICD (International Classification of Disease) revision at the time of death. Person-years at risk ended in 1998 for all those known to have been alive in 1979 when the NDI became available, or else at the date of death, or at the date last observed for those lost to follow-up prior to 1979. I relied on cause-of-death information from the NDI (NDI-Plus), and did not obtain new death certificates for this follow-up extension.

Analyses comparing welders and nonwelders to the US population were conducted using the life-table anal- ysis system of the National Institute for Occupational Safety and Health (3), adjusted for age (5-year categories), race (white or nonwhite), and calendar time (5year categories). Direct comparisons between the welders and nonwelders, adjusted for age (5-year categories), race, and calendar time (5-year categories) were conducted via Poisson regression (4).

\section{Results}

Table 1 presents the results for a variety of causes for the welders and nonwelders in comparison with the US population. The welders showed an increase in lung cancer rate when compared with that of the earlier followup, with a standardized mortality ratio of 1.46 , while the nonwelders had approximately the same ratio as before, 1.18. Overall mortality was unremarkable for both cohorts, as was that for heart disease and nonmalignant respiratory disease. Both kidney cancer and bladder cancer were in excess among the welders but not among the nonwelders, although the numbers were relatively small. Emphysema was markedly increased for both groups and therefore suggested a possible effect of smoking among these blue-collar workers when compared with the US population. In contrast, larynx cancer and esophageal cancer, two other diseases strongly related to smoking, did not show marked increases, although small numbers limited precision for these outcomes. Furthermore, the category "other nonmalignant respiratory disease", most of which was nonspecific chronic obstructive pulmonary disease, which is also highly related to smoking, did not show an excess.

No deaths from asbestosis or nonspecific pneumoconiosis occurred in either the welder or the nonwelder cohort; this finding tends to confirm the lack of asbestos exposure. One death from mesothelioma occurred in a welder (as reported in our prior study of this cohort, follow-up through 1988). This man had 20 years of prior employment in a brewery, an industry with potential asbestos exposure. Because I did not obtain death certificates for the workers covered by my new followup, but instead relied on cause-of-death information from the NDI, and because mesothelioma does not have its own specific ICD code, I was not able to review death certificates for the occurrence of mesothelioma in the new follow-up. There were no deaths from cancer of the pleura or peritoneum - two categories that sometimes include mesotheliomas - in either the welder or nonwelder cohort.

A direct comparison of the welders and nonwelders via Poisson regression yielded a rate ratio of 1.22 (95\% CI 0.93-1.59) for lung cancer. Direct 
Table 1. Mortality from selected causes for the welders and nonwelders in comparison with that of the United States population. (SMR = standardized mortality ratio, $95 \% \mathrm{Cl}=95 \%$ confidence interval)

\begin{tabular}{|c|c|c|c|c|c|c|}
\hline \multirow[t]{2}{*}{ Cause $^{a}$} & \multicolumn{3}{|c|}{ Welders } & \multicolumn{3}{|c|}{ Nonwelders } \\
\hline & Deaths & SMR & $95 \% \mathrm{Cl}$ & Deaths & SMR & $95 \% \mathrm{Cl}$ \\
\hline All cancers & 258 & 1.25 & $1.09-1.41$ & 326 & 1.07 & $0.96-1.19$ \\
\hline Lung cancer (162) & 108 & 1.46 & $1.20-1.76$ & 128 & 1.18 & $0.98-1.40$ \\
\hline Esophageal cancer (150) & 4 & 0.61 & $0.16-1.55$ & 5 & 0.60 & $0.19-1.40$ \\
\hline Laryngeal cancer (161) & 4 & 1.42 & $0.39-3.62$ & 5 & 1.26 & $0.40-2.94$ \\
\hline Prostate cancer (185) & 12 & 0.96 & $0.49-1.68$ & 36 & 1.57 & $1.10-2.17$ \\
\hline Colon cancer (152-153) & 19 & 1.12 & $0.67-1.75$ & 22 & 0.83 & $0.51-1.25$ \\
\hline Kidney cancer (189.0-189.2) & 10 & 1.84 & $0.88-3.38$ & 6 & 0.77 & $0.28-1.68$ \\
\hline Bladder cancer $(188,189.3-189.9)$ & 7 & 1.71 & $0.69-3.53$ & 9 & 1.21 & $0.55-2.30$ \\
\hline Ischemic heart disease (410-414) & 203 & 0.99 & $0.86-1.14$ & 323 & 0.92 & $0.82-1.03$ \\
\hline $\begin{array}{l}\text { All nonmalignant respiratory disease } \\
(460-466,470-478,480-487,490-519)\end{array}$ & 58 & 1.12 & $0.85-1.44$ & 87 & 0.97 & $0.77-1.20$ \\
\hline Emphysema (492) & 13 & 1.94 & $1.03-3.32$ & 23 & 1.74 & $1.10-2.61$ \\
\hline Bronchitis & 2 & 1.27 & $0.19-2.67$ & 5 & 1.95 & $0.63-4.56$ \\
\hline $\begin{array}{l}\text { Other nonmalignant respiratory diseases } \\
(470-478,494-519)\end{array}$ & 28 & 1.12 & $0.75-1.62$ & 44 & 1.03 & $0.74-1.38$ \\
\hline All causes & 808 & 0.95 & $0.88-1.01$ & 1161 & 0.94 & $0.88-0.99$ \\
\hline
\end{tabular}

a Codes of the International Classification of Diseases, 9th revision, in parenthesis.

Table 2. Standardized mortality ratios (SMR) and standardized rate ratios (SRR) for lung cancer among the welders and nonwelders. (US = United States, $95 \% \mathrm{Cl}=95 \%$ confidence interval)

\begin{tabular}{|c|c|c|c|c|c|c|c|c|}
\hline & \multicolumn{3}{|c|}{ Welders versus US population } & \multicolumn{3}{|c|}{ Nonwelders versus US population } & \multicolumn{2}{|c|}{ Welders versus nonwelder } \\
\hline & $\begin{array}{l}\text { Deaths } \\
\text { (N) }\end{array}$ & SMR & $95 \% \mathrm{Cl}$ & $\begin{array}{l}\text { Deaths } \\
(\mathrm{N})\end{array}$ & SMR & $95 \% \mathrm{Cl}$ & SRR & $95 \% \mathrm{Cl}$ \\
\hline Lung cancer mortality & 108 & 1.46 & $1.20-1.76$ & 128 & 1.18 & $0.90-1.40$ & 1.22 & $0.93-1.59$ \\
\hline \multicolumn{9}{|l|}{ Duration of exposure } \\
\hline $\begin{array}{l}2-5 \text { years } \\
5-10 \text { years } \\
10-15 \text { years } \\
15-20 \text { years } \\
>20 \text { years }\end{array}$ & $\begin{array}{l}32 \\
22 \\
24 \\
15 \\
15\end{array}$ & $\begin{array}{l}1.55 \\
1.34 \\
1.91 \\
1.29 \\
1.19\end{array}$ & $\begin{array}{l}1.06-2.19 \\
0.84-2.03 \\
1.22-2.84 \\
0.72-2.13 \\
0.67-1.96\end{array}$ & $\begin{array}{l}21 \\
21 \\
16 \\
23 \\
47\end{array}$ & $\begin{array}{l}1.25 \\
1.60 \\
1.03 \\
1.02 \\
1.16\end{array}$ & $\begin{array}{l}0.77-1.91 \\
0.99-2.45 \\
0.59-1.67 \\
0.65-1.53 \\
0.85-1.54\end{array}$ & $\begin{array}{l}1.26 \\
0.88 \\
1.47 \\
1.22 \\
1.06\end{array}$ & $\begin{array}{l}0.71-2.21 \\
0.47-1.66 \\
0.75-2.86 \\
0.63-2.38 \\
0.59-1.90\end{array}$ \\
\hline \multicolumn{9}{|l|}{ Latency } \\
\hline $\begin{array}{l}<20 \text { years } \\
\geq 20 \text { years }\end{array}$ & $\begin{array}{l}22 \\
86\end{array}$ & $\begin{array}{l}1.38 \\
1.48\end{array}$ & $\begin{array}{l}0.86-2.09 \\
1.18-1.83\end{array}$ & $\begin{array}{r}27 \\
101\end{array}$ & $\begin{array}{l}0.98 \\
1.25\end{array}$ & $\begin{array}{l}0.65-1.43 \\
1.11-1.52\end{array}$ & $\begin{array}{l}1.26 \\
1.21\end{array}$ & $\begin{array}{r}0.70-2.27 \\
-0.90-1.63\end{array}$ \\
\hline
\end{tabular}

welder to nonwelder comparisons for emphysema and other nonmalignant respiratory disease (primarily nonspecific chronic obstructive pulmonary disease) yielded standardized rate ratios of $1.09(0.54-2.18)$ and $1.16(0.71-1.90)$, respectively.

Table 2 gives more detailed results for lung cancer for both standardized mortality ratios (comparing welders and nonwelders to the U.S. population) and standardized rate ratios (comparing welders to nonwelders). There was no positive trend indicating an increased risk of lung cancer with increased duration of exposure for the welders, for either the standardized mortality ratios or the standardized rate ratios. There was some inaccuracy involved in the duration results and latency because I did not update the work histories of the workers who were currently employed at the time of the data collection in the mid-1980s (14\% of the cohort). There was little suggestion of any increase among the welders with a longer latency, when either standardized mortality ratios or standardized rate ratios were considered.

The data were also analyzed with a 15-year lag time (table 3). The results did not change markedly. There was a suggestion of a trend with duration for the standardized rate ratios when the welders and nonwelders were compared. However, the category with the longest exposure did not show an elevated rate ratio. A test for trend in the internal analyses via Poisson regression, using either years of exposure $(\mathrm{P}=0.33)$ or the $\log$ of years of exposure $(\mathrm{P}=0.17)$ as a continuous variable, did not indicate a strong positive trend. 
Table 3. Standardized mortality ratios (SMR) and standardized rate ratios (SRR) for lung cancer among the welders and nonwelders, 15 year lag time. (US = United States, 95\% Cl=95\% confidence interval)

\begin{tabular}{|c|c|c|c|c|c|c|c|c|}
\hline & \multicolumn{3}{|c|}{ Welders versus US population } & \multicolumn{3}{|c|}{ Nonwelders versus US population } & \multicolumn{2}{|c|}{ Welders versus nonwelders } \\
\hline & $\begin{array}{l}\text { Deaths } \\
(\mathrm{N})\end{array}$ & SMR & $95 \% \mathrm{Cl}$ & $\begin{array}{l}\text { Deaths } \\
(\mathrm{N})\end{array}$ & SMR & $95 \% \mathrm{Cl}$ & SRR & $95 \% \mathrm{Cl}$ \\
\hline Total mortality & $97^{\mathrm{a}}$ & 1.47 & $1.19-1.79$ & $114^{\star}$ & 1.18 & $0.90-1.40$ & 1.22 & $0.93-1.59$ \\
\hline \multicolumn{9}{|c|}{ Duration of exposure } \\
\hline $\begin{array}{l}2-5 \text { years } \\
5-10 \text { years } \\
10-15 \text { years } \\
15-20 \text { years } \\
>20 \text { years }\end{array}$ & $\begin{array}{l}34 \\
23 \\
23 \\
12 \\
15\end{array}$ & $\begin{array}{l}1.39 \\
1.30 \\
1.94 \\
1.65 \\
1.02\end{array}$ & $\begin{array}{l}0.96-1.94 \\
0.82-1.95 \\
1.23-2.91 \\
0.85-2.88 \\
0.57-1.68\end{array}$ & $\begin{array}{l}32 \\
26 \\
20 \\
15 \\
21\end{array}$ & $\begin{array}{l}1.30 \\
1.33 \\
1.09 \\
0.97 \\
1.33\end{array}$ & $\begin{array}{l}0.89-1.89 \\
0.87-1.95 \\
0.66-1.68 \\
0.54-1.60 \\
0.82-2.07\end{array}$ & $\begin{array}{l}1.10 \\
0.89 \\
1.69 \\
1.63 \\
0.77\end{array}$ & $\begin{array}{l}0.67-1.81 \\
0.49-1.59 \\
0.92-3.11 \\
0.75-3.51 \\
0.29-2.05\end{array}$ \\
\hline \multicolumn{9}{|l|}{ Latency a } \\
\hline $\begin{array}{l}<20 \text { years } \\
\geq 20 \text { years }\end{array}$ & $\begin{array}{l}66 \\
31\end{array}$ & $\begin{array}{l}1.39 \\
1.66\end{array}$ & $\begin{array}{l}1.07-1.77 \\
1.23-2.36\end{array}$ & $\begin{array}{l}77 \\
37\end{array}$ & $\begin{array}{l}1.11 \\
1.52\end{array}$ & $\begin{array}{l}0.88-1.39 \\
1.07-2.10\end{array}$ & $\begin{array}{l}1.20 \\
1.10\end{array}$ & $\begin{array}{l}0.88-1.64 \\
0.67-1.79\end{array}$ \\
\hline
\end{tabular}

a Eleven welders and 14 nonwelders were lagged out in this analysis and not included in table 3.

Plant-specific analyses were also conducted. Welders at plants 1,2, and 3 had standardized mortality ratios of 1.08 (95\% CI $0.57-1.84,13$ deaths observed), 1.65 (95\% CI 1.29-2.07, 74 deaths observed), and 1.24 (95\% CI $0.77-1.90,21$ deaths observed), respectively, for lung cancer, while the corresponding ratios for the nonwelders were 1.12 (95\% CI $0.76-1.59,31$ deaths observed), 1.23 (95\% CI $0.87-1.68,39$ deaths observed), and 1.18 (95\% CI $0.90-1.53,58$ deaths observed). I found no explanation for the concentration of welder excess in plant 2 , especially since exposures were considered similar at all three plants. However, the confidence intervals were wide for the welders of plants 1 and 3 , and therefore random error may have been responsible.

\section{Discussion}

Mortality from lung cancer among the welders, when compared with that of the general population, increased markedly when compared with the results of the earlier follow-up (from a lung cancer SMR of 1.07 to an SMR of 1.46), while the standardized mortality ratio for the nonwelders remained virtually the same. A direct comparison between the welders and nonwelders yielded a rate ratio of 1.22.

Both welders $(\mathrm{N}=891)$ and nonwelders $(\mathrm{N}=4731)$ smoked more than the general population in a crosssectional survey in $1985 ; 22 \%$ of the welders and $21 \%$ of the nonwelders were never-smokers, compared with $30 \%$ of the US population of the same age and gender. More welders than nonwelders were cur- rent smokers (49\% versus $42 \%)$ in 1985, and fewer were former smokers (29\% versus 37\%). The corresponding figures for current and former smokers in the United States were $36 \%$ and $34 \%$, respectively. A calculation to estimate the likely effect of confounding by smoking in a direct comparison of the welders to nonwelders (5), on the assumption of a rate ratio of 15 for current smokers and 5 for former smokers, indicated that the expected rate ratio between the welders and nonwelders would be approximately 1.08 due to smoking differences alone, while the expected rate ratio between the welders and the US population would be 1.23 . These rate ratios expected from smoking differences alone should be compared with the respective observed rate ratios of 1.22 for welders versus nonwelders, and 1.46 for welders versus the US population. Thus there appears to have been a modest excess of lung cancer among the welders as compared with either the nonwelders or the US population, beyond what would be expected due to smoking differences. However, the smoking data were limited and did not provide a basis for solid inference about the effects of smoking versus exposure on lung cancer rates.

The trends for increased lung cancer risk for welders with increased duration or increased latency were not pronounced or were inconsistent, although there was a suggestion of a trend with duration for the analysis with a 15-year lag time. It should be remembered, however, that the duration of exposure may not be well correlated with cumulative exposure to welding fumes, the measure of interest. The degree of this correlation depends on whether the intensity of exposure changed over time or varied across different kinds of welding jobs. 
In conclusion, 10 additional years of follow-up have brought these data more in line with other welder data sets in showing some evidence of an excess of lung cancer among welders when compared with either the general population or another population of nonwelders in the same plants. These mild-steel welders did not have occupational exposure to asbestos, nickel, or chromium, and therefore these agents could not have been responsible for any of the lung cancer excess. However, smoking differences between the welders and the US population, and between the welders and the nonwelders, are likely to have accounted for at least part of the lung cancer excess found for the welders. The present data are suggestive, but not conclusive, with regard to whether mild-steel welding results in an increased risk of lung cancer.

\section{References}

1. Steenland K, Beaumont J, Elliot L, Lung cancer in mild steel welders. Am J Epidemiol 1991;133:220-29.

2. Moulin JJ. A meta-analysis of epidemiologic studies of lung cancer in welders. Scand J Work Environ Health 1997;23: 104-13.

3. Steenland K, Spaeth S, Cassinelli R, Laber P, Chang L, Koch K. NIOSH life table program for personal computers. Am J Ind Med 1998;34:517-8.

4. SAS Institute Inc. SAS user's guide: statistics (version 6.07). Cary (NC): SAS Institute Inc, 1991.

4. Axelson O, Steenland K. Indirect methods of assessing tobacco use in occupational studies. Am J Ind Med 1988;13(1): 105-18.

Received for publication: 22 March 2002 